\title{
MIGRAÇÃO E EMPREGO PRECÁRIO EM DOIS CONTEXTOS DISTINTOS: São Paulo e Toritama
}

\author{
Renato Santos Duarte* \\ Wilson Fusco*
}

\begin{abstract}
O artigo tem por objetivo fazer uma comparação entre os trabalhadores do setor de confecção de vestuário e acessórios, em duas cidades distintas: a capital paulista e a pequena Toritama, situada no Agreste pernambucano. Foram considerados, na cidade de São Paulo, somente os imigrantes cearenses que trabalham nesse setor, cujo número era próximo do total de pessoas ocupadas na mesma atividade em Toritama. Foram utilizados os microdados do Censo de 2000. De um modo geral, a informalidade se mostrou expressiva nos dois contextos, embora um pouco mais elevada em Toritama. O artigo mostra que a maioria dos trabalhadores na atividade de confecção, nas duas cidades, era mal remunerada, tinha jornadas de trabalho acima do padrão, não possuía carteira assinada e poucos contribuíam para a Previdência Social. Considerando os custos monetários e não monetários da vida na capital paulista, não ficou evidente que os imigrantes cearenses estudados estivessem em melhor situação que os trabalhadores de Toritama.

PALAVRAS-CHAVE: migração, emprego precário, confecção de vestuário e acessórios, São Paulo, Toritama.
\end{abstract}

\section{INTRODUÇÃO}

A capital de São Paulo, ao assumir o papel hegemônico em praticamente todos os ramos da indústria brasileira, na primeira metade do século $\mathrm{XX}$, transformou-se no principal pólo da indústria têxtil e de confecções do Brasil. Muitos dos migrantes que se transferiram para a capital paulista encontraram ocupação nas indústrias e nas atividades terciárias que, subsidiariamente, iam surgindo e se expandindo (Stein, 1979; Cano, 1977). Da região Nordeste - como antes havia ocorrido, principalmente nos períodos de secas - milhares de pessoas se deslocaram para a região Sudeste, em especial para o estado de São Paulo. Um dos estados nordestinos que mais se tem notabilizado como emissor de migrantes é o Ceará. Por razões diversas, de resto comuns a outros estados nor-

*Doutor pela University of Glasgow (Escócia). Pesquisador Titular da Fundação Joaquim Nabuco.

Rua Dois Irmãos, 92. Apipucos. Cep: 52071-440 - Recife - PE - Brasil. r_s duarte@hotmail.com

**Doutor em Demografia pela Unicamp. Pesquisador Assistente da Fundação Joaquim Nabuco. wilson.fusco@fundaj.gov.br destinos, mas particularmente por ser aquele que, historicamente, mais tem sido castigado pelas secas episódicas, ${ }^{1}$ o êxodo de cearenses para outras regiões do país é um fenômeno que se incorporou a uma das imagens associadas àquele estado (Martine \& Camargo, 1984). Uma primeira observação dos dados do Censo de 2000 mostra que, naquele ano, o número de cearenses ocupados na atividade de confecção de roupas (6.025 pessoas) no município de São Paulo era bastante aproximado do número de trabalhadores (6.003 pessoas) do mesmo ramo industrial em Toritama, pequena cidade do Agreste de Pernambuco. Desse modo, a comparação entre os migrantes cearenses ocupados na indústria paulista de confecções e os trabalhadores do mesmo setor em Toritama - independentemente do seu estado de origem - pareceu cientificamente interessante, a par da semelhança acima referida, no tocante ao número de trabalhadores empregados desse subsetor das Indústrias de transformação, nas duas cidades.

${ }^{1}$ O Ceará é o único estado nordestino que está inteiramente dentro do chamado "Polígono das Secas". 
A comparação da situação de trabalhadores em contextos tão distintos parece ainda mais interessante quando se considera o papel proeminente desempenhado pelo estado e pela cidade de São Paulo, em maior ou menor intensidade, ao longo dos anos, como lugar de destino de emigrantes nordestinos. Apesar do fenômeno recente - já amplamente estudado pelos especialistas - da migração de retorno da população nordestina desde o Sudeste, revelado pelo Censo de 1991 e confirmado pelo Censo de 2000 (Cunha \& Baeninger, 2005), era considerável o contingente de nordestinos residentes no município de São Paulo. Merece destaque, a propósito, o percentual de imigrantes nordestinos ocupados na atividade de confecção de vestuário $(3,4 \%)$, uma vez que, dentre os não naturais do estado de São Paulo, eles constituíam 51\% dos ocupados nessa atividade. Além disso, a indústria paulista de confecções tem passado por mudanças ao longo dos anos, podendose destacar, como exemplos, a utilização, em período recente, de mão-de-obra estrangeira - principalmente imigrantes bolivianos, indocumentados, na sua maioria (Silva, 2006) - e, ainda mais recentemente, a concorrência, no mais das vezes ilegal, da indústria chinesa. Esse é um problema que afeta toda a indústria de confecções do país.

A cidade de Toritama é um caso recente de sucesso econômico, surgido na esteira de outro fenômeno sem paralelo no Brasil: a indústria da sulanca, que teve início na década de 1970, no município vizinho de Santa Cruz do Capibaribe, na zona do Agreste pernambucano (Xavier, 2006). A indústria da sulanca constitui um caso particularmente interessante do processo de industrialização do Nordeste, pelo seu caráter espontâneo e autônomo, e que surgiu no auge - e à margem - da política de incentivo oficial à indústria proporcionado pelo Fundo de Industrialização do Nordeste (Finor), administrado pela Superintendência do Desenvolvimento do Nordeste (Sudene). No início da década de 1970, os caminhoneiros que transportavam mercadorias da sub-região do Agreste pernambucano para o estado de São Paulo defrontavam-se, freqüentemente, com a falta de carga para trazer na viagem de retorno. Ocorreu a alguns desses caminhoneiros a idéia de comprar retalhos do tecido chamado helanca e transportá-los para serem aproveitados pelas costureiras de Santa Cruz do Capibaribe, que experimentavam uma fase de ociosidade, devida, principalmente, aos custos relativamente altos de matéria-prima para a confecção de roupas (Xavier, 2006). A parceria entre os caminhoneiros e as costureiras de Santa Cruz do Capibaribe prosperou e consolidou-se em curto espaço de tempo, chegando a caracterizar uma atividade que veio a ser batizada com o nome de indústria da sulanca. ${ }^{2} \mathrm{~A}$ expansão da indústria de confecção naquela pequena porção do Agreste de Pernambuco deve-se a uma conjunção de fatores, dentre os quais vale destacar a proximidade da cidade de Caruaru, que, além de ser um importante pólo econômico sub-regional, abriga a maior feira ao ar livre do interior nordestino. Sem Caruaru, dificilmente a indústria da sulanca teria prosperado em Santa Cruz do Capibaribe; sem esta, provavelmente Toritama teria continuado a exibir o pouco dinamismo que ainda hoje se observa na maioria das cidades do Agreste pernambucano.

$\mathrm{O}$ fato concreto é que Toritama tornou-se o maior pólo de confecções do Nordeste, a ponto de ser responsável, hoje, pela fabricação de 15\% dos jeans produzidos no país. As mudanças ocorridas em Toritama ao longo da década de 1990, em decorrência da expansão da atividade de confecção de roupas, manifestaram-se de diversas formas. Dentre essas transformações, merece destaque, neste artigo, o crescente fluxo de imigrantes em busca de oportunidades de trabalho no setor de confecções, bem como nas outras atividades subsidiárias. Comparar duas realidades tão diferentes parece relevante, tanto para se conhecerem as eventuais diferenças nos processos de absorção dos imigrantes, quanto nas condições de trabalho no mesmo ramo industrial surgido em contextos econômicos diferentes, em espaços territoriais distantes e em fases distintas da formação histórica do Brasil. Para uma avaliação detalhada da indústria da sulanca,
ver Fade, UFPE (2003). 


\section{ABORDAGENS SOBRE EMPREGO E MIGRA- ÇÃO}

As décadas de 1980 e 1990 foram marcadas, no Brasil e no resto do mundo, por crises econômicas que ensejaram o surgimento de idéias originais e a proposição de novas políticas macro e microeconômicas. O ideário neoliberal - que pregava a redução do tamanho e do papel do Estado na condução das decisões econômicas nacionais, transferindo-as para as forças de mercado - foi aplicado, com maior ou menor ênfase, em quase todas as economias capitalistas. Uma das conseqüências da "onda" neoliberal foi a adoção da chamada reestruturação produtiva que, como a expressão sugere, advogava a introdução de medidas de caráter geral visando à reorganização das empresas (Borges, 2006). Por trás das propostas de reestruturação produtiva estava a idéia de busca de maior eficiência e produtividade. Daí foram surgindo, dentre os muitos efeitos colaterais, formas de precarização das condições de trabalho. $\mathrm{O}$ fenômeno da terceirização - contratação de serviços prestados por firmas especializadas para a realização de determinadas tarefas que antes faziam parte da linha de produção da empresa contratante - levou ao enxugamento do quadro de pessoal de muitas empresas de médio e grande porte. No Brasil - como em outros países - a redução da jornada de trabalho e a opção por não assinar a carteira de trabalho dos empregados foi outra faceta da precarização que tomou vulto na última década do século XX. O aumento do número de trabalhadores sem carteira assinada, no Brasil, no período de 1992 a 2001, foi de 5,4\% (Baltar, 2003). Os trabalhadores sem carteira assinada, na maioria das vezes, deixam de pagar sua contribuição previdenciária. Então, a precarização torna-se mais acentuada, porque, além de não contar com qualquer segurança trabalhista, o empregado deixa de usufruir os direitos sociais que a legislação assegura aos contribuintes. Por outro lado, a Previdência Social, que enfrenta custos crescentes que dificilmente superará - seja pelo crescimento vegetativo da população, seja pelo pagamento de aposenta- dorias sem a correspondente contribuição, aprovada pela Constituição de 1988 -, vê-se mergulhada em situações deficitárias preocupantes. Como forma de escapar do desemprego, milhões de brasileiros vêem-se compelidos a se submeter a condições de trabalho que representam as mais variadas formas de precarização, que podem culminar, muitas vezes, em situações subumanas (idem).

Sobre migrações internas, existe uma vasta literatura internacional e brasileira, como se pode ver no volumoso trabalho organizado por Hélio Moura (Moura, 1980: 2t.). Dentre as várias contribuições feitas por diversos autores, uma das questões mais discutidas é a que trata das razões que levam as pessoas a emigrar. De um lado, são discutidos os fatores de expulsão, ou seja, os problemas - a exemplo do desemprego ou dos baixos rendimentos - que levam as pessoas a deixarem seus lugares de origem em busca de melhores condições de vida em outras localidades. No caso dos habitantes do sertão nordestino, as secas episódicas têm sido causadoras do êxodo de famílias rurais para as áreas urbanas do próprio Nordeste ou para outras regiões do país (Duarte, 1979). Como a maioria dos habitantes do Sertão sobrevive da agricultura de subsistência, dependente de água das chuvas, qualquer interrupção dessas (seja em termos espaciais, seja no calendário das precipitações) provoca a perda da safra e leva milhões de pessoas à situação de indigência. Com o fim de amenizar os efeitos sociais das secas, as políticas oficiais de socorro aos flagelados das secas terminam por contribuir, também, para reduzir a intensidade do êxodo e, portanto, para atenuar as conseqüências que as hordas de pessoas famintas trariam para as áreas urbanas da região e do país (GTDN, 1967).

Outra corrente de estudiosos das migrações atribui aos fatores de atração nos lugares de destino o motivo para a decisão das pessoas de emigrar. No seu estudo clássico sobre salários, Hicks (1932) afirmava que a decisão de emigrar decorria da expectativa de maximização de alguma utilidade, como a renda ou o emprego. Para outros autores, como Lee (1966) e Herrick (1970), aquela decisão resulta de fatores combinados de expulsão e 
atração. Todaro (1969) acredita que, nos países pobres, apesar do conhecimento da existência de altas taxas de desemprego e subemprego nas áreas urbanas, os emigrantes rurais agem racionalmente, visto que eles levam em conta não o presente, mas os diferenciais futuros de renda. Outro adepto da predominância dos fatores de atração, Glantz (1973: FRB $n^{\circ}$ 52), argumenta que os migrantes escolhem os lugares de destino onde, esperam, irão receber benefícios sociais e ter acesso a melhores serviços públicos.

Outra questão sempre presente nos estudos sobre migrações diz respeito aos determinantes que mais contam na escolha do lugar de destino. Seria a localidade em si? Ou a distância do deslocamento? Seria a presença, ali, de parentes e (ou) amigos? Ou a oferta de trabalho? A presença de parentes e amigos tem sido apontada como um elemento importante na escolha do lugar de destino, inclusive pela possibilidade que têm aquelas pessoas de contribuir para a atenuação dos custos psicológicos e materiais decorrentes da mudança (Duarte, 1979). Outra contribuição relevante dada às teorias das migrações foi feita por Hägerstrand (1957: LSG $n^{\circ}$ 13), ao advogar que a distribuição espacial dos migrantes é uma conseqüência da presença de pessoas que os antecederam.

No Brasil, o estado de São Paulo, no decorrer de boa parte do século XX (mais intensamente nas décadas de 1960 e 1970), tornou-se uma área de atração de migrantes, graças ao dinamismo observado nos setores industrial e agrícola, e nos subsetores que constituem o terciário. Vários estudos demonstraram que a presença de parentes e amigos contribuiu, também, para a escolha do estado e da cidade de São Paulo como lugares de destino de migrantes de todas as regiões do país (Tassara \& Rabinovich, 2007; Veras et al, 1987).

\section{OS CONTEXTOS ANALISADOS}

A atividade de confecção em Toritama absorvia $58,3 \%$ dos trabalhadores ocupados no ano 2000 , como se vê na Tabela 1. O subsetor mais importante em termos de absorção da mão-de-obra toritamense,

Tabela 1 - Toritama e São Paulo: distribuição da população ocupada segundo setor de atividade - 2000

\begin{tabular}{|c|c|c|}
\hline \multirow{3}{*}{ Atividades } & \multicolumn{2}{|c|}{ Município } \\
\hline & Toritama & São Paulo (nascidos no CE) \\
\hline & $(\%)$ & $(\%)$ \\
\hline Mal especificadas & 0,29 & 1,53 \\
\hline Agricultura, pecuária, silvicultura, explor. florest. e pesca & 6,48 & 0,29 \\
\hline Indústrias extrativas & 0,00 & 0,03 \\
\hline Indústrias de transformação & 61,69 & 19,86 \\
\hline (Confecção de artigos do vestuário e acessórios) & $(58,31)$ & $(4,58)$ \\
\hline Produção e distribuição de eletricidade, gás e água & 0,11 & 0,26 \\
\hline Construção & 2,44 & 9,12 \\
\hline Comércio; repar. de veículos automot., obj. pessoais e dom. & 12,08 & 19,43 \\
\hline Alojamento e alimentação & 2,19 & 14,15 \\
\hline Transporte, armazenagem e comunicações & 1,55 & 6,42 \\
\hline Intermediação financeira & 0,00 & 1,48 \\
\hline Atividades imobiliárias, aluguéis e serv. prest. às empresas & 0,54 & 8,47 \\
\hline Administração pública, defesa e seguridade social & 2,88 & 1,56 \\
\hline Educação & 1,94 & 2,28 \\
\hline Saúde e serviços sociais & 0,50 & 2,78 \\
\hline Outros serviços coletivos, sociais e pessoais & 3,40 & 3,65 \\
\hline Serviços domésticos & 3,91 & 8,70 \\
\hline Total (\%) & 100,00 & 100,00 \\
\hline
\end{tabular}


depois de confecção, era o comércio, principalmente aquele realizado em postos móveis ou mercados. Fica evidente, nessa tabela, que a atividade de confecção de vestuário e acessórios ocupava mais da metade da mão-de-obra desse município, que se especializou na indústria de confecção de uso popular. As atividades comerciais, por sua vez, estavam relacionadas, predominantemente, com a distribuição das mercadorias produzidas pela indústria de confecção. A mencionada tabela mostra, por outro lado, que a distribuição ocupacional dos imigrantes cearenses na cidade de São Paulo era mais diversificada, ainda que o setor de Indústrias de Transformação representasse o maior grupo de ocupados (19,9\%) e, dentro desse, o subsetor de confecção fosse também o mais importante, com 4,6\%. Uma análise mais detida das atividades dos cearenses em São Paulo revela que os demais setores, em ordem de importância na absorção dos trabalhadores, eram: Alojamento e Alimentação (14,2\%), Construção (9,1\%), Serviços Domésticos (8,7\%) e Atividades Imobiliárias (8,5\%). Na verdade, esse cenário evidenciava uma maior concentração setorial da mão-de-obra de cearenses na confecção frente à população nordestina na capital paulista, visto que, em 2000, o setor de confecção de vestuário e acessórios empregava apenas 3,4\% das pessoas provenientes do Nordeste, enquanto que os naturais do Ceará somavam 4,6\%, como anteriormente mencionado.

Do total de 21.800 pessoas residentes em Toritama no ano 2000 , mais da metade $(57,2 \%)$ tinha idade entre 0 e 24 anos, o que se mostra consistente com o perfil demográfico das cidades do interior nordestino, onde a taxa de fecundidade é relativamente elevada quando comparada com a da população das regiões Sul e Sudeste. Por outro lado, no mesmo ano, 61,5\% dos 235.249 imigrantes cearenses residentes na cidade de São Paulo tinham idade entre 20 e 44 anos. A diferença entre os perfis demográficos de Toritama e São Paulo se deve, no caso dessa cidade, à diminuição de crianças e adolescentes no movimento imigratório (as faixas de idade de 0 a 14 anos concentravam somente $16,0 \%$ dos migrantes recentes) e ao fato de os filhos de imigrantes nascidos na capital paulista terem naturalidade paulistana. No tocante à participação da mão-de-obra ocupada na indústria de confecção das duas cidades, vê-se, na Tabela 2, que havia uma concentração maior de jovens em Toritama (66,0\%) nas faixas etárias entre 15 e 29 anos, enquanto que, em São Paulo, 56,3\% das pessoas naturais do Ceará ocupadas nessa atividade tinham idade entre 30 e 49 anos. Essa diferença pode encontrar explicação - além da diferença na composição por idade de cada população

Tabela 2 - Toritama e São Paulo: distribuição da população ocupada na atividade de confecção segundo faixas de idade e sexo - 2000

\begin{tabular}{|c|c|c|c|c|}
\hline \multirow{3}{*}{ Faixa de Idade } & \multicolumn{4}{|c|}{ Município } \\
\hline & \multicolumn{2}{|c|}{ Toritama (\%) } & \multicolumn{2}{|c|}{ São Paulo (\%) (nascidos no CE) } \\
\hline & Masculino & Feminino & Masculino & Feminino \\
\hline 10 a 14 & 6,66 & 1,30 & 1,42 & 0,00 \\
\hline 15 a 19 & 20,66 & 17,85 & 10,07 & 3,11 \\
\hline 20 a 24 & 27,51 & 27,69 & 13,24 & 5,79 \\
\hline 25 a 29 & 20,45 & 17,33 & 18,60 & 12,84 \\
\hline 30 a 34 & 9,69 & 14,99 & 16,30 & 12,58 \\
\hline 35 a 39 & 7,21 & 9,14 & 12,91 & 13,75 \\
\hline 40 a 44 & 3,67 & 4,37 & 4,49 & 14,77 \\
\hline 45 a 49 & 1,67 & 4,96 & 7,22 & 17,73 \\
\hline 50 a 54 & 1,58 & 1,41 & 5,03 & 10,90 \\
\hline 55 а 59 & 0,00 & 0,63 & 5,58 & 4,56 \\
\hline 60 e mais & 0,91 & 0,33 & 5,14 & 3,97 \\
\hline \multirow[t]{2}{*}{ Total $(\%)$} & 100,00 & 100,00 & 100,00 & 100,00 \\
\hline & (3301) & $(2701)$ & $(914)$ & (5111) \\
\hline
\end{tabular}


- no fato de, nas grandes cidades, ao contrário do que ocorre nos pequenos núcleos urbanos, a população jovem dedicar maior número de anos aos estudos, inclusive à freqüência de cursos de capacitação, que costumam existir em maior quantidade e diversidade nas cidades de maior porte.

A Tabela 2 mostra ainda uma diferença digna de registro quanto à distribuição das pessoas ocupadas, por sexo, na atividade de confecção, nas duas cidades. Enquanto, em Toritama, os homens correspondiam a $55 \%$ das pessoas ocupadas na atividade de confecção, em São Paulo, ocorria o oposto: as mulheres representavam a grande maioria (85\%) dos trabalhadores nesse subsetor econômico. Uma possível explicação para isso pode estar na diversificação do mercado de trabalho da cidade de São Paulo, onde a gama de opções do mercado de trabalho oferece oportunidades de emprego caracteristicamente masculinas, a exemplo de operários da construção civil, de trabalhadores nas indústrias metalúrgica e mecânica, de motoristas, de porteiros e vigilantes, de militares etc.

\section{Perfil migratório}

Os dados do Censo revelam também que, no ano 2000, 68,5\% dos moradores de Toritama eram naturais do município que nunca haviam migrado, ou seja, $31,5 \%$ dos residentes correspondiam ao estoque de imigrantes. Se os 185 municípios de Pernambuco fossem hierarquizados em ordem decrescente pela proporção de imigrantes, Toritama estaria na $48^{\mathrm{a}}$ posição, o que sugere a existência de relativa atratividade, comparativamente aos demais municípios do estado. ${ }^{3}$

Com relação aos toritamenses ocupados na atividade de confecção, a proporção de imigrantes era ainda maior (38,6\%), o que indica a importância do setor na atratividade migratória local. O tempo médio de residência em Toritama, para esses imigrantes, era de 9,4 anos, o que, em princípio, já lhes conferia as características de nativos do município. O estoque de imigrantes ocupados no setor de confecção em Toritama era formado por 80,0\% de pernambucanos - dentre os quais $9,2 \%$ eram retornados plenos (nascidos em Toritama) -, 8,0\% de alagoanos, 4,8\% de paulistas, 4,6\% de paraibanos e $2,6 \%$ divididos entre paranaenses, mineiros, potiguares e cearenses. A maioria dos imigrantes nascidos fora do estado de Pernambuco (464 pessoas) chegou a Toritama durante os 10 anos anteriores ao ano 2000. Com relação aos migrantes recentes (com menos de 10 anos de residência na UF), aproximadamente $30 \%$ deles fizeram um longo trajeto a partir do estado de São Paulo e quase $50 \%$ vieram dos vizinhos estados de Alagoas e Paraíba.

O censo 2000 mostra que o tempo médio de residência dos imigrantes cearenses no município de São Paulo era de 17,7 anos; ou seja, a rigor já estavam integrados e, objetivamente, grande parte deles não deveria ser considerada migrante. O censo revela também que 20,6\% dos imigrantes cearenses residentes no município de São Paulo (1.239) vieram de outras unidades da federação nos 10 anos anteriores ao censo, sendo que - além da maioria vinda diretamente do Ceará - $5,5 \%$ passaram pelo estado da Bahia e 2,1\% fizeram escala no Rio de Janeiro, o que revela quais as principais etapas na migração dessas pessoas. A forma de distribuição dos imigrantes recentes no município (chegados há menos de 10 anos e correspondentes a 32,7\% do total de imigrantes) apresentava regularidade no decorrer do período, não indicando uma diminuição de volume nos anos próximos a 2000. Considerando a diferença entre esses e os retornados ao Ceará, no mesmo período, São Paulo ficou com um saldo positivo de 7.312 imigrantes cearenses, número ínfimo quando são considerados os saldos de décadas anteriores. Essa é uma evidência a mais do fenômeno de desconcentração da indústria no município de São Paulo, que se foi consolidando no decorrer da década de 1990.

Além disso, os dados da contagem de 2007 mostram que Toritama teve uma taxa de crescimento de $4,6 \%$ ao ano, a maior do estado, no período de 2000 a 2007 . 


\section{Perfil ocupacional}

A Tabela 3 mostra que, como seria de esperar, os rendimentos médios, medidos em número de salários mínimos, eram mais altos para os cearenses em São Paulo do que para os trabalhadores em Toritama, tanto na ocupação principal de todos os trabalhadores quanto no setor de confecções. No entanto, considerando a diferença no custo de vida (alimentação, habitação, serviços públicos e pessoais) entre as cidades de São Paulo e Toritama, é possível que o rendimento médio real fosse equivalente nas duas cidades. Ademais, se forem levados em conta os custos não-monetários (tempo para deslocamentos na cidade, poluição sonora e atmosférica, índice de violência etc.) da vida na capital de São Paulo, não há condição para inferir que as diferenças salariais reveladas na Tabela 3 constituíam uma vantagem para os cearenses que trabalhavam nessa cidade, comparativamente aos Toritamenses ocupados na mesma atividade, na mesma época.

A Tabela 4 mostra os níveis de instrução, em termos de anos de estudo, dos toritamenses e dos cearenses ocupados no setor de confecções da cidade de São Paulo. Como seria de esperar, a es- colaridade dos trabalhadores em São Paulo era superior aos de Toritama: 41,1\% com escolaridade entre 5 e 8 anos na capital paulista e 29,9\% na cidade do Agreste pernambucano. Além disso, os cearenses ocupados na atividade de confecções em São Paulo que tinham 9 anos ou mais de estudo representavam 21,3\%, comparativamente aos 11,4\% de trabalhadores do mesmo setor em Toritama. A média de anos de estudo corrobora a interpretação anterior, uma vez que a população em Toritama tinha 4,2 enquanto que os cearenses em São Paulo exibiam 6,1. A composição etária entre os grupos analisados poderia ter papel importante nessa diferença, mas a padronização por idade não confirmou essa hipótese. Como é sabido, em cidades maiores, as exigências por parte do mercado de trabalho quanto à escolaridade da mão-de-obra é maior do que em cidades pequenas.

Da mesma maneira, os dados da Tabela 5 corroboram a expectativa existente acerca de maior formalidade - representada pela carteira de trabalho assinada - em São Paulo, comparativamente com Toritama. Esse é, aliás, o aspecto mais marcante na distinção entre as duas cidades relativamente à inserção das respectivas populações no mercado de trabalho. Nas grandes cidades brasileiras, exis-

Tabela 3 - Toritama e São Paulo: salário médio dos trabalhadores no setor de atividade de confecção e acessórios e nos setores de atividade em geral - 2000

\begin{tabular}{l|c|c}
\multicolumn{2}{c}{ Faixa de Idade } & \multicolumn{2}{c}{ Salário médio (em salários-mínimos) } \\
\cline { 2 - 3 } & Toritama (\%) & São Paulo (\%) (nascidos no CE) \\
\hline Todos os setores & 2,5 & 4,5 \\
\hline Confecção de vestuário e acessórios & 2,4 & 3,2 \\
\hline
\end{tabular}

Fonte: IBGE Censo Demográfico 2000. Tabulação própria.

Tabela 4 - Toritama e São Paulo: distribuição da população ocupada no setor de atividade de confecção e acessórios segundo número de anos de estudo e sexo - 2000

\begin{tabular}{|c|c|c|c|c|}
\hline \multirow{3}{*}{ Anos de Estudo } & \multicolumn{4}{|c|}{ Município } \\
\hline & \multicolumn{2}{|c|}{ Toritama (\%) } & \multicolumn{2}{|c|}{ São Paulo (\%) (nascidos no CE) } \\
\hline & Masculino & Feminino & Masculino & Feminino \\
\hline Sem instrução ou menos de 1 ano & 17,06 & 9,32 & 5,79 & 3,24 \\
\hline 1 a 4 anos & 48,65 & 40,73 & 35,96 & 33,62 \\
\hline 5 a 8 anos & 25,99 & 34,70 & 35,41 & 42,10 \\
\hline 9 a 11 anos & 7,91 & 14,10 & 20,22 & 19,35 \\
\hline 12 e mais & 0,39 & 1,15 & 2,62 & 1,68 \\
\hline \multirow[t]{2}{*}{ Total $(\%)$} & 100,00 & 100,00 & 100,00 & 100,00 \\
\hline & (3301) & $(2703)$ & $(\mathbf{9 1 5})$ & $(5110)$ \\
\hline
\end{tabular}

Fonte: IBGE Censo Demográfico 2000. Tabulação própria. 
Tabela 5 - Toritama e São Paulo: distribuição da população ocupada no setor de atividade de confecção e acessórios segundo status ocupacional e sexo - 2000

\begin{tabular}{|c|c|c|c|c|}
\hline \multirow{3}{*}{ Status ocupacional } & \multicolumn{4}{|c|}{ Município } \\
\hline & \multicolumn{2}{|c|}{ Toritama (\%) } & \multicolumn{2}{|c|}{ São Paulo (\%) (nascidos no CE) } \\
\hline & Masculino & Feminino & Masculino & Feminino \\
\hline Empregado com carteira de trab. assinada & 5,39 & 3,48 & 41,31 & 32,25 \\
\hline Empregado sem carteira de trab. assinada & 73,67 & 81,24 & 34,43 & 29,08 \\
\hline Empregador & 4,45 & 0,37 & 8,52 & 1,39 \\
\hline Conta-própria & 16,48 & 11,47 & 15,74 & 37,28 \\
\hline Aprendiz ou estágio sem remuneração & 0,00 & 0,37 & 0,00 & 0,00 \\
\hline Não remunerado em ajuda a membro do domicílio & 0,00 & 3,07 & 0,00 & 0,00 \\
\hline \multirow[t]{2}{*}{ Total $(\%)$} & 100,00 & 100,00 & 100,00 & 100,00 \\
\hline & (3301) & $(2703)$ & $(\mathbf{9 1 5})$ & (5110) \\
\hline
\end{tabular}

Fonte: IBGE Censo Demográfico 2000. Tabulação própria.

te uma melhor compreensão-decorrente, em grande parte, do comportamento dos Juízes do Trabalho ao julgarem questões laborais - das conseqüências que poderão advir do desrespeito aos direitos legais dos trabalhadores assalariados. Pode-se atribuir a percentagem expressivamente mais elevada de trabalhadores por conta própria ao tempo de residência (que pode ter favorecido o conhecimento do mercado de roupas populares) e ao reconhecido empreendedorismo de muitos imigrantes, sendo que, no Brasil, os cearenses têm se destacado. Em atividades predominantemente informais, e nas localidades onde é relativamente alto o número de pessoas com poucos anos de estudo, a existência de aprendizes e de membros da família não remunerados costuma ser mais elevado que nas grandes cidades.

Consistentemente com as informações apresentadas na tabela anterior, vê-se, na Tabela 6, que os percentuais de trabalhadores no mercado formal do setor de confecção nas duas cidades eram baixos. Mesmo em São Paulo, mais da metade
$(57,1 \%)$ dos trabalhadores nessa atividade não era contribuinte; em Toritama, o percentual era de 92,5\%, um número muito alto. A contribuição (ou não) para a Previdência Social é outra forma - juntamente com a assinatura da carteira de trabalhode se avaliar o nível de formalidade (ou informalidade) na economia. Outro aspecto digno de menção na Tabela 5 é o percentual elevado $(37,3 \%)$ de mulheres que trabalhavam por conta própria em São Paulo. A explicação para isso está, provavelmente, no fato de, no município de São Paulo, ser elevado o número de mulheres que trabalhavam na atividade de confecção sob medida, como se verá adiante.

A visão conjunta dos dados apresentados nas Tabelas 5 e 6 é reveladora de uma grande informalidade no setor de confecção de vestuário e acessórios nas duas cidades, lançando luz, ademais, sobre a fragilidade das relações trabalhistas em São Paulo, a maior cidade do país. Esse problema afigura-se ainda mais grave se for considerado que, na capital paulista, existe um grande nú-

Tabela 6 - Toritama e São Paulo: distribuição da população ocupada no setor de atividade de confecção e acessórios segundo status de contribuição a Previdência oficial e sexo - 2000

\begin{tabular}{|c|c|c|c|c|}
\hline \multirow{3}{*}{$\begin{array}{l}\text { Era contribuinte de Instituto de Previdência } \\
\text { oficial? }\end{array}$} & \multicolumn{4}{|c|}{ Município } \\
\hline & \multicolumn{2}{|c|}{ Toritama (\%) } & \multicolumn{2}{|c|}{ São Paulo (\%) (nascidos no CE } \\
\hline & Masculino & Feminino & Masculino & Feminino \\
\hline em trab. na semana ou aprendizes Sem remun. & 5,39 & 6,95 & 41,31 & 32,24 \\
\hline im & 1,76 & 1,11 & 15,96 & 8,10 \\
\hline Vão & 92,85 & 91,94 & 42,73 & 59,66 \\
\hline otal $(\%)$ & 100,00 & 100,00 & 100,00 & 100,00 \\
\hline & $(3301)$ & $(2704)$ & (915) & (5111) \\
\hline
\end{tabular}

Fonte: IBGE Censo Demográfico 2000. Tabulação própria. 
mero de oficinas de confecção clandestinas. Outra maneira de averiguar o nível de informalidade é por meio da observação do número de horas trabalhadas, porquanto jornadas menores que o padrão de 40 horas sugerem subutilização e as longas jornadas indicam sobre-utilização da mão-deobra. Como mostra a Tabela 7, pouco mais da metade dos trabalhadores nas duas cidades trabalhavam entre 41 e 60 horas, apontando para algum tipo de sobre-utilização da mão-de-obra. Essa dedução parece ainda mais séria ao se constatar, como mostram as tabelas 3 e 4 , quão baixos eram os salários naquela atividade, nas duas cidades estudadas. Segundo o Censo 2000, o percentual de pessoas aposentadas como trabalhadores no setor de confecção era baixo, sendo um pouco maior na cidade de São Paulo, o que é compreensível, visto que a indústria de confecção da capital paulista é bem mais antiga que a de Toritama.

A distribuição dos trabalhadores na atividade de confecção, por sexo, é algo a ser tratado como uma questão de gênero, como pode ser visto na Tabela 8. Nesse aspecto, vê-se uma diferença apreciável nas duas cidades, sendo que, em Toritama, havia um equilíbrio na distribuição de trabalhado- res de ambos os sexos na confecção de vestuário e acessórios, (sob medida ou não), enquanto que, em São Paulo, as pessoas ocupadas nessa atividade eram predominantemente do sexo feminino, evidenciando a existência ali de um nicho ocupacional para mulheres. Além disso, em São Paulo, cerca de 80\% dos trabalhadores do sexo feminino dedicavam-se à confecção (exceto sob medida), e pouco mais de 19\% trabalhavam na fabricação de roupas e acessórios, sob medida ou não. Por outro lado, mais da metade $(53,2 \%)$ dos trabalhadores do sexo masculino trabalhavam em empresas de confecção de roupas, na categoria "sob medida ou não". Essa categoria, que não apresentou representantes dentre os trabalhadores em Toritama, corresponde a ocupações dentro de empresas do setor de confecções, mas que, na maioria, não estavam relacionadas à operação de máquinas de costura. Uma possível explicação para esse fenômeno poderia estar no fato de que, em empresas de médio e grande porte, existiam várias atividades polivalentes (almoxarife, motorista, vigilante etc.), ao contrário do que ocorria em Toritama, onde quase a totalidade dos trabalhadores dedicava-se diretamente às atividades de confecção.

Tabela 7 - Toritama e São Paulo: distribuição da população ocupada no setor de atividade de confecção e acessórios segundo número de horas trabalhadas - 2000

\begin{tabular}{l|c|c}
\hline \multirow{2}{*}{ Número de horas trabalhadas por semana } & \multicolumn{2}{c}{ Município } \\
\cline { 2 - 3 } & Toritama (\%) & São Paulo (\%) (nascidos no CE) \\
\hline Até 40 horas & 40,12 & 38,60 \\
\hline 41 a 60 horas & 55,45 & 54,23 \\
\hline Mais que 60 horas & 4,43 & 7,17 \\
\hline Total (\%) & 100,00 & 100,00 \\
\hline & $\mathbf{( 6 0 0 4 )}$ & $\mathbf{( 6 0 2 3 )}$ \\
\hline
\end{tabular}

Fonte: IBGE Censo Demográfico 2000. Tabulação própria.

Tabela 8 - Toritama e São Paulo: distribuição da população ocupada no setor de atividade de confecção e acessórios segundo subclassificação no setor de atividade e sexo - 2000

\begin{tabular}{|c|c|c|c|c|}
\hline \multirow{3}{*}{$\begin{array}{c}\text { Confecção de artigos do vestuário } \\
\text { e acessórios }\end{array}$} & \multicolumn{4}{|c|}{ Município } \\
\hline & \multicolumn{2}{|c|}{ Toritama (\%) } & \multicolumn{2}{|c|}{ São Paulo (\%) (nascidos no CE) } \\
\hline & Masculino & Feminino & Masculino & Feminino \\
\hline Exceto sob medida & 85,67 & 83,02 & 41,14 & 80,08 \\
\hline Sob medida & 14,33 & 16,98 & 5,69 & 11,84 \\
\hline Sob medida ou não & 0,00 & 0,00 & 53,17 & 8,08 \\
\hline \multirow[t]{2}{*}{ Total (\%) } & 100,00 & 100,00 & 100,00 & 100,00 \\
\hline & (3301) & $(2703)$ & (914) & $(5110)$ \\
\hline
\end{tabular}

Fonte: IBGE Censo Demográfico 2000. Tabulação própria. 


\section{CONSIDERAÇÕES FINAIS}

Este artigo procurou comparar as condições de trabalho no setor de confecção de vestuário e acessórios em dois contextos econômicos e populacionais muito distintos: a cidade pernambucana de Toritama e a capital paulista. No caso dessa última, foram considerados somente os imigrantes cearenses, de modo a tornar comparáveis os números. Os imigrantes cearenses em São Paulo ali residiam, em média, há 17 anos, o que se explica pelo fato de o boom migratório do Nordeste para o estado de São Paulo ter ocorrido nas décadas de 1950 e 1960. Por outro lado, Toritama passou a se tornar um local de destino de migrantes mais recentemente, a partir dos anos de 1980 e 1990, quando se ampliou o pólo de confecção do Agreste pernambucano.

O trabalho revelou diferenças - como seria de esperar - nas condições de trabalho no setor de confecção de dois contextos tão diferentes. De um modo geral, os indicadores de informalidade se mostraram expressivos nas duas cidades, embora, também compreensivelmente, mais elevados na cidade de Toritama. Pelo que foi visto neste artigo, os trabalhadores na atividade de confecção nas duas cidades eram mal remunerados, tinham jornadas de trabalho superiores ao padrão de 40 horas semanais, na sua maioria não tinham carteira assinada e poucos contribuíam para a Previdência Social. Considerando os custos monetários e não monetários da vida na cidade de São Paulo, não parece evidente que os imigrantes cearenses ocupados no setor de confecção dessa cidade estivessem em melhor situação que os de Toritama. Talvez seja por isso que esta cidade vem recebendo um forte e persistente influxo de migrantes (inclusive de retorno) nos últimos anos, induzido pela expansão da atividade de confecção de vestuário e acessórios. Outra constatação interessante diz respeito à predominância de mulheres no trabalho de confecção de roupas na cidade de São Paulo, comparativamente a Toritama, onde era mais equilibrada a distribuição, nessa atividade, por sexo. Esse fenômeno talvez encontre explicação na di- versificação do mercado de trabalho na capital paulista, em que é maior a oferta de ocupações tipicamente masculinas, ou preferidas pelos trabalhadores do sexo masculino. É digno de registro, também, o número expressivo de mulheres, em São Paulo, ocupadas na confecção de roupas sob medida (daí o percentual relativamente elevado de trabalhadores por conta própria), situação essa que não era significativa em Toritama. Além disso, é importante observar que, além da pouca diversidade econômica de uma cidade pequena, no caso de Toritama, a proeminência da indústria de confecção levou a que as outras atividades, principalmente o comércio, fossem muito dependentes da atividade predominante.

(Recebido para publicação em setembro de 2007) (Aceito em abril de 2008)

\section{REFERÊNCIAS}

BALTAR, P. E. A. O mercado de trabalho no Brasil dos anos 90. Tese (Livre-Docência) - Instituto de Economia, Universidade Estadual de Campinas, Campinas, 2003.

BORGES, Ângela. "Impactos do desemprego e da precarização sobre famílias metropolitanas". Revista Brasileira de Estudos de População, São Paulo, v. 23, n.2, 2006, p. 205-222.

CANO, W. Raízes da concentração industrial em São Paulo. São Paulo, Difel, 1977.

CUNHA, José M. P. da.; BAENINGER, Rosana A. Cenários da Migração no Brasil nos Anos 90. Cadernos do CRH, UFBA - Salvador, Bahia, v. 18, n. 43, p. 87-101, 2005.

DUARTE, R. S. Migration and Urban Poverty in Northeast Brazil. Tese de $\mathrm{PhD}$, submetida à Universidade de Glasgow. Março de 1979.

FADE / UFPE. Estudo de Caracterização Econômica do Pólo de Confecções do Agreste Pernambucano. FADE UFPE/SEBRAE: Recife, 2003. Relatório de Pesquisa.

GLANTZ, F. B. The Determinants of the Intermetropolitan Migration of the Economically Disadvantaged. Federal Reserv Bank of Boston Research Report n. 52, January 1973.

GTDN. Uma política de desenvolvimento econômico para o Nordeste. $2^{\mathrm{a}}$ ed. Recife: Sudene, 1967.

HÄGERSTRAND, T. Migration and Area, in Migration in Sweden: a Symposium. Lund Studies in Geography. Series B, Human Geography N. 13. Lund, Sweden, C.W.K. Gleerup, 1957.

HERRICK, B. Urbanization and Urban Migration in Latin America: an Economist's View, in Rabinovitz, F. and Trueblood, F. Latin America Urban Research, v. 1, Beverley Hills, Sage Publications, 1970.

HICKS, J. R. The theory of wages, London, Macmillan, 1932. 
IBGE - Instituto Brasileiro de Geografia e Estatística. Censo Demográfico de 2000. Rio de Janeiro: IBGE, 2000.

LEE, Everet S. A theory of Migration. Demography, 3 (1), 1966.

LYRA, M. R. S. B. SULANCA X MUAMBA: rede social que alimenta a migração de retorno. Revista São Paulo em Perspectiva. v. 19, p. 144-154, 2005.

MARTINE, G. \& CAMARGO, L. Crescimento e distribuição da população brasileira: tendências recentes. Revista Brasileira de Estudos de População, Campinas - SP, 1 (1/ 2), jan/dez 1984, p. 99-144.

MONTALI, L. T. Relação Família-Trabalho: reestruturação produtiva e desemprego. Revista São Paulo em Perspectiva, São Paulo, v. 17, n. abril-jun, p. 123-135, 2003.

Rearranjos Familiares de Inserção, Precarização do Trabalho e Empobrecimento. Revista Brasileira de Estudos de População, Campinas - SP, v. 21, n. 2, p. 195216, 2004

MOURA, Hélio Augusto de (Org.). Migração Interna. Fortaleza: Banco do Nordeste do Brasil, 1980, 2 t.

"O balanço migratório do Nordeste no período 1950/70". In (Org ) Migração Interna. Fortaleza: Banco do Nordeste do Brasil, 1980, p.1.025 - 1.072.

SANTOS, Loraine M. dos; MOREIRA, Ivan T.; Condições do Mercado de Trabalho no Setor de Serviços Nordestino. Anais do XV Encontro Nacional de Estudos Populacionais, ABEP, realizado em Caxambu MG - Brasil, de 18 a 22 de setembro de 2006.

\section{MIGRATION AND PRECARIOUS LABOR IN TWO DIFFERENT CONTEXTS: São Paulo and Toritama}

\author{
Renato Santos Duarte \\ Wilson Fusco
}

This paper aims to do a comparison between workers of the clothes and accessories making sector in two different cities: the capital from São Paulo and small Toritama, located in Pernambuco hinterland. Only the immigrants from Ceará that work in that sector were considered in the city of São Paulo, which number was close to that of the total of employed people in the same activity in Toritama. Microdata of the Census of 2000 were used. In general, informality was expressive in both contexts, although a little higher in Toritama. This paper shows that most of the workers in cholthes making, in the two cities, were badly paid, had work days above the pattern, weren't registered, and few contributed to Social Welfare. Considering the monetary non monetary and costs of life in the capital from São Paulo, it was not evident that the immigrants from Ceará studied were in better situation than the workers of Toritama.

KEYworDs: migration, precarious labor, clothes and accessories making, São Paulo, Toritama.
SILVA, Sidney A. da. Bolivianos em São Paulo: entre o sonho e a realidade. Estudos Avançados. [online]. 2006, vol. 20, no. 57, pp. 157-170.

STEIN, S.J. Origem e Evolução da Indústria Têxtil no Brasil: 1850-1950. Rio de Janeiro: Editora Campus, 1979.

TASSARA, Eda T. de O. e RABINOVICH, Elaine P. Movimentos migratórios na metrópole de São Paulo no século XXI: um estudo quali-quantitativo. Estud. pesqui. psicol. [online]. dez. 2007, v. 7, no.3.

TODARO, Michael J.; Income Expectations, Rural - Urban Migration and Employment in Africa. In: Jolly, Richard; de Kadt, E.; Singer, H. and Wilson, F. editors, Third World Employment: problems and strategy, London, Cox and Wyman Ltd., 1976.

VERAS, Renato P; RAMOS, Luiz Roberto; KALACHE Alexandre. The increase of the elderly population in Brazil: transformation of and consequences for society. Rev. Saúde Pública, São Paulo, v. 21, n. 3, 1987.

XAVIER, M. G. P. O empreendedorismo em Cidades do Interior de Pernambuco: estudo de caso em Santa Cruz do Capibaribe (1960-2000). 2006. Tese (Doutorado em Desenvolvimento Urbano) - Universidade Federal de Pernambuco

\section{MIGRATIONET EMPLOI PRÉCAIRE DANS DEUX CONTEXTES DIFFÉRENTS: Sao Paulo et Toritama}

\author{
Renato Santos Duarte \\ Wilson Fusco
}

Lobjectif de cette étude est de faire une comparaison entre les travailleurs qui confectionnent des vêtements et des accessoires dans deux villes différentes : la capitale de l'Etat de Sao Paulo et de la petite ville de Toritama, située dans la région agreste de l'Etat de Pernambouc. A Sao Paulo, seuls les immigrants du Céara qui travaillent dans ce secteur et dont le nombre est proche du nombre total de personnes qui occupent cette même activité à Toritama, ont été pris en considération. Nous avons utilisé les micro données du Recensement de 2000. D’une manière générale, l'informalité a été utilisée dans les deux contextes, même si elle a été un peu plus élevée à Toritama. L'article montre que dans les deux villes, la majorité des ouvriers travaillant dans la confection était mal rémunérée, faisait des heures de travail au-dessus de la moyenne, n'avait pas de contrat de travail et que peu d'ouvriers cotisaient à la Sécurité Sociale. Si l'on prend en considération le coût monétaire et non monétaire de la vie dans la capitale de l'Etat de Sao Paulo, il n'est pas évident que les immigrants de l'Etat du Ceara, qui ont fait l'objet de notre étude, vivent dans de meilleures conditions que les ouvriers de Toritama.

Mots-clés: migration, emploi précaire, confection de vêtements et d'accessoires, São Paulo, Toritama. 